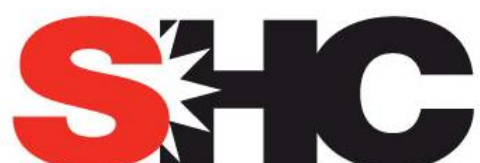

SOLAR HEATING \& COOLING PROGRAMME INTERNATIONAL ENERGY AGENCY
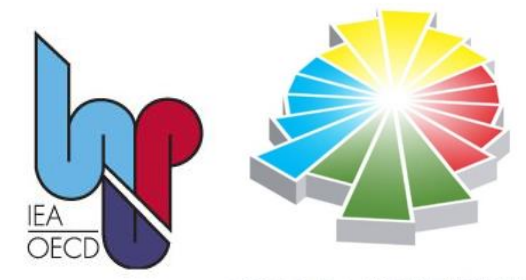

SOLAR + HEAT PUMP

\title{
Presentation of system performance calculation Educational material
}

A technical report of subtask D

Date: $\mathbf{2 8 . 1 0 . 2 0 1 3}$

By Matteo D'Antoni

${ }^{1}$ Eurac Research, Institute for Renewable Energy

Viale Druso 1

I - 39100 Bolzano

Phone: $\quad+390471055614$

Fax: $\quad$ +390471 055699

e-mail: matteo.dantoni@eurac.edu 


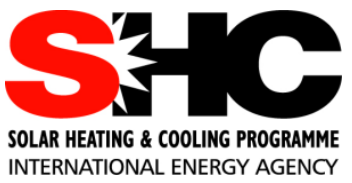

\section{IEA Solar Heating and Cooling Programme}

The International Energy Agency (IEA) is an autonomous body within the framework of the Organization for Economic Co-operation and Development (OECD) based in Paris. Established in 1974 after the first "oil shock," the IEA is committed to carrying out a comprehensive program of energy cooperation among its members and the Commission of the European Communities.

The IEA provides a legal framework, through IEA Implementing Agreements such as the Solar Heating and Cooling Agreement, for international collaboration in energy technology research and development (R\&D) and deployment. This IEA experience has proved that such collaboration contributes significantly to faster technological progress, while reducing costs; to eliminating technological risks and duplication of efforts; and to creating numerous other benefits, such as swifter expansion of the knowledge base and easier harmonization of standards.

The Solar Heating and Cooling Programme was one of the first IEA Implementing Agreements to be established. Since 1977, its members have been collaborating to advance active solar and passive solar and their application in buildings and other areas, such as agriculture and industry. Current members are:

$\begin{array}{lll}\text { Australia } & \text { Finland } & \text { Singapore } \\ \text { Austria } & \text { France } & \text { South Africa } \\ \text { Belgium } & \text { Italy } & \text { Spain } \\ \text { Canada } & \text { Mexico } & \text { Sweden } \\ \text { Denmark } & \text { Netherlands } & \text { Switzerland } \\ \text { European Commission } & \text { Norway } & \text { United States } \\ \text { Germany } & \text { Portugal } & \end{array}$

A total of 49 Tasks have been initiated, 35 of which have been completed. Each Task is managed by an Operating Agent from one of the participating countries. Overall control of the program rests with an Executive Committee comprised of one representative from each contracting party to the Implementing Agreement. In addition to the Task work, a number of special activitiesMemorandum of Understanding with solar thermal trade organizations, statistics collection and analysis, conferences and workshops - have been undertaken.

Visit the Solar Heating and Cooling Programme website - www.iea-shc.org - to find more publications and to learn about the SHC Programme. 
Current Tasks \& Working Group:

Task $36 \quad$ Solar Resource Knowledge Management

Task $39 \quad$ Polymeric Materials for Solar Thermal Applications

Task $40 \quad$ Towards Net Zero Energy Solar Buildings

Task $41 \quad$ Solar Energy and Architecture

Task $42 \quad$ Compact Thermal Energy Storage

Task $43 \quad$ Solar Rating and Certification Procedures

Task $44 \quad$ Solar and Heat Pump Systems

Task $45 \quad$ Large Systems: Solar Heating/Cooling Systems, Seasonal Storages, Heat Pumps

Task $46 \quad$ Solar Resource Assessment and Forecasting

Task $47 \quad$ Renovation of Non-Residential Buildings Towards Sustainable Standards

Task $48 \quad$ Quality Assurance and Support Measures for Solar Cooling

Task $49 \quad$ Solar Process Heat for Production and Advanced Applications

Completed Tasks:

Task 1

Task 2

Task 3

Task 4

Task 5

Task 6

Task 7

Task 8

Task 9

Task 10

Task 11

Task 12

Task 14

Task 16

Task 17

Task 18

Task 20

Task 22

Task 23

Task 24

Task 25

Task 26

Task 27

Task 28

Task 29

Task 31

Task 32

Task 33

Task 34

Task 35

Task 37

Task 38
Task 13

Task 19

Task 21

Investigation of the Performance of Solar Heating and Cooling Systems

Coordination of Solar Heating and Cooling $R \& D$

Performance Testing of Solar Collectors

Development of an Insolation Handbook and Instrument Package

Use of Existing Meteorological Information for Solar Energy Application

Performance of Solar Systems Using Evacuated Collectors

Central Solar Heating Plants with Seasonal Storage

Passive and Hybrid Solar Low Energy Buildings

Solar Radiation and Pyranometry Studies

Solar Materials $R \& D$

Passive and Hybrid Solar Commercial Buildings

Building Energy Analysis and Design Tools for Solar Applications

Advanced Solar Low Energy Buildings

Advanced Active Solar Energy Systems

Photovoltaics in Buildings

Measuring and Modeling Spectral Radiation

Advanced Glazing and Associated Materials for Solar and Building Applications

Solar Air Systems

Solar Energy in Building Renovation

Daylight in Buildings

Building Energy Analysis Tools

Optimization of Solar Energy Use in Large Buildings

Solar Procurement

Solar Assisted Air Conditioning of Buildings

Solar Combisystems

Performance of Solar Facade Components

Solar Sustainable Housing

Solar Crop Drying

Daylighting Buildings in the 21st Century

Advanced Storage Concepts for Solar and Low Energy Buildings

Solar Heat for Industrial Processes

Testing and Validation of Building Energy Simulation Tools

PV/Thermal Solar Systems

Advanced Housing Renovation with Solar \& Conservation

Solar Thermal Cooling and Air Conditioning

Completed Working Groups:

CSHPSS; ISOLDE; Materials in Solar Thermal Collectors; Evaluation of Task 13 Houses; Daylight Research 


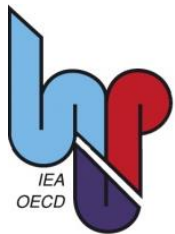

\section{IEA Heat Pump Programme}

This project was carried out within the Solar Heating and Cooling Programme and also within the Heat Pump Programme, HPP which is an Implementing agreement within the International Energy Agency, IEA. This project is called Task 44 in the Solar Heating and Cooling Programme and Annex 38 in the Heat pump Programme.

The Implementing Agreement for a Programme of Research, Development, Demonstration and Promotion of Heat Pumping Technologies (IA) forms the legal basis for the IEA Heat Pump Programme. Signatories of the IA are either governments or organizations designated by their respective governments to conduct programmes in the field of energy conservation.

Under the IA collaborative tasks or "Annexes" in the field of heat pumps are undertaken. These tasks are conducted on a cost-sharing and/or task-sharing basis by the participating countries. An Annex is in general coordinated by one country which acts as the Operating Agent (manager). Annexes have specific topics and work plans and operate for a specified period, usually several years. The objectives vary from information exchange to the development and implementation of technology. This report presents the results of one Annex. The Programme is governed by an Executive Committee, which monitors existing projects and identifies new areas where collaborative effort may be beneficial.

\section{The IEA Heat Pump Centre}

A central role within the IEA Heat Pump Programme is played by the IEA Heat Pump Centre (HPC). Consistent with the overall objective of the IA the HPC seeks to advance and disseminate knowledge about heat pumps, and promote their use wherever appropriate. Activities of the HPC include the production of a quarterly newsletter and the webpage, the organization of workshops, an inquiry service and a promotion programme. The HPC also publishes selected results from other Annexes, and this publication is one result of this activity.

For further information about the IEA Heat Pump Programme and for inquiries on heat pump issues in general contact the IEA Heat Pump Centre at the following address:

\section{IEA Heat Pump Centre}

Box 857

SE-501 15 BORÅS

Sweden

Phone: +4610165512

Fax: +4633131979

Visit the Heat Pump Programme website - http://www.heatpumpcentre.org/ - to find more publications and to learn about the HPP Programme.

Legal Notice Neither the IEA Heat Pump Centre nor the SHC Programme nor any person acting on their behalf: (a) makes any warranty or representation, express or implied, with respect to the information contained in this report; or (b) assumes liabilities with respect to the use of, or damages, resulting from the use of this information. Reference herein to any specific commercial product, process, or service by trade name, trademark, manufacturer, or otherwise, does not necessarily constitute or imply its endorsement recommendation or favouring. The views and opinions of authors expressed herein do not necessarily state or reflect those of the IEA Programmes, or any of its employees. The information herein is presented in the authors' own words. 


\section{Contents}

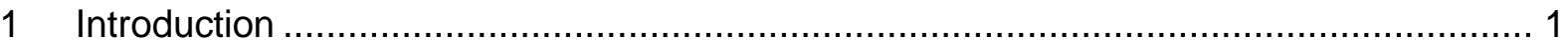

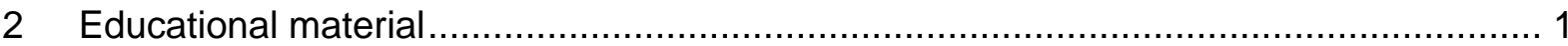




\section{Introduction}

IEA Task 44 / Annex 38 has produced free available educational material on the subject of performance figures evaluation for Solar plus Heat Pump (SHP) systems. The aim is to develop supporting material useful during teaching activities on the topic of Solar plus Heat Pump systems.

The content addresses the definition of several performance indicators developed within Task 44 / Annex 38. The material has been derived from the activities of Subtask B. More detailed information on this topic can be found in the deliverable B1. In the final slides an example is additionally presented for clarifying the relevance and the meaning of each single performance figure.

The material has a form of a presentation. Since the idea is to guide hand-in-hand the reader in the process of SHP analysis, the format is clear and communicative and clarifying text and graphs correlate indicator's definition.

It is free downloadable from the Task 44 / Annex 38 webpage (http://task44.iea-shc.org).

\section{Educational material}

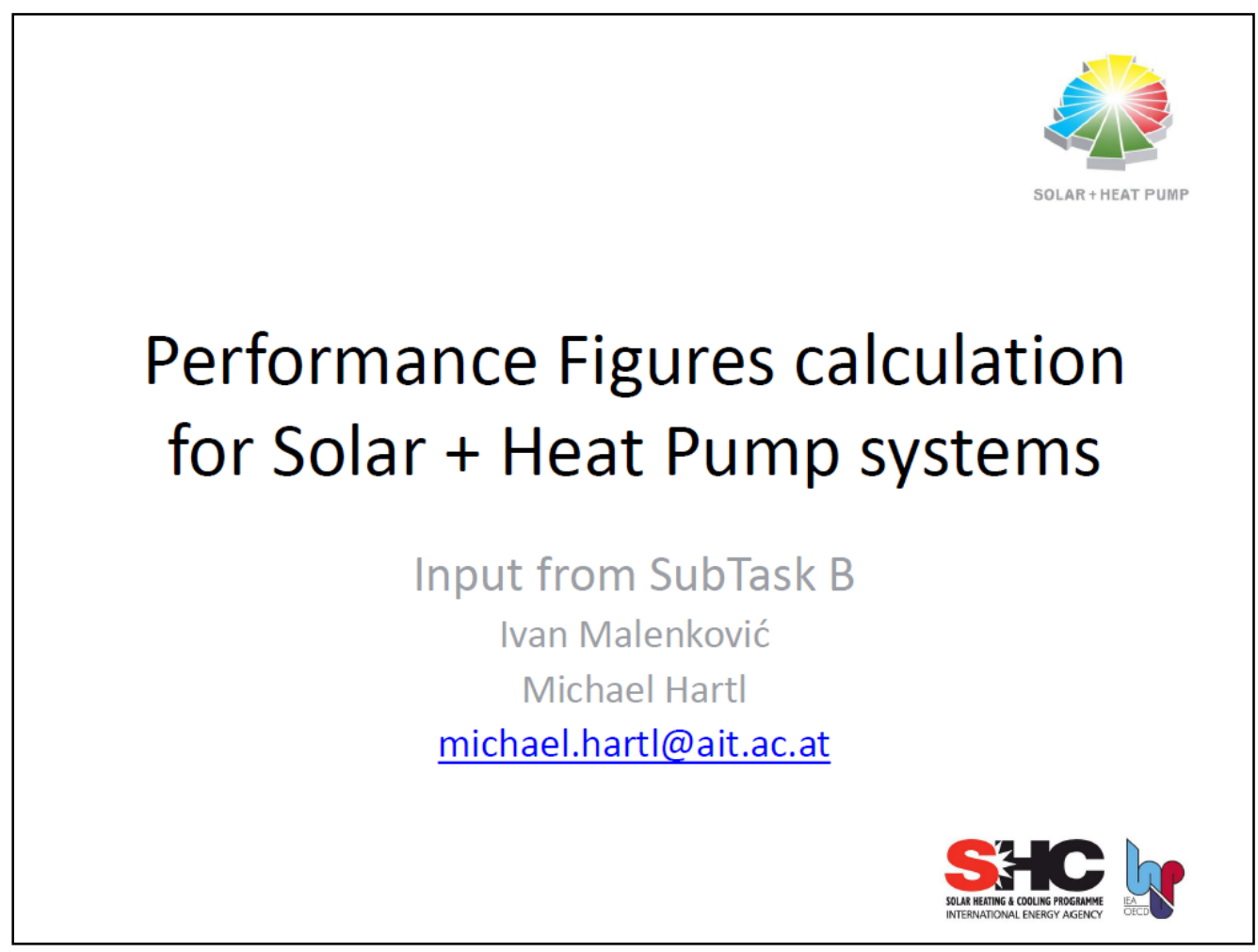




\section{Disclaimer}

This presentation contains material collected and produced by partecipants to Task 44 / Annex 38 of the International Energy Agency (IEA) Solar Heating and Cooling Programme / Heat Pump Programme.

\section{Performance Evaluation of SHP Systems}

- Transparent and fair comparison of different SHP system configurations AND

- Comparison to other heating and cooling technologies

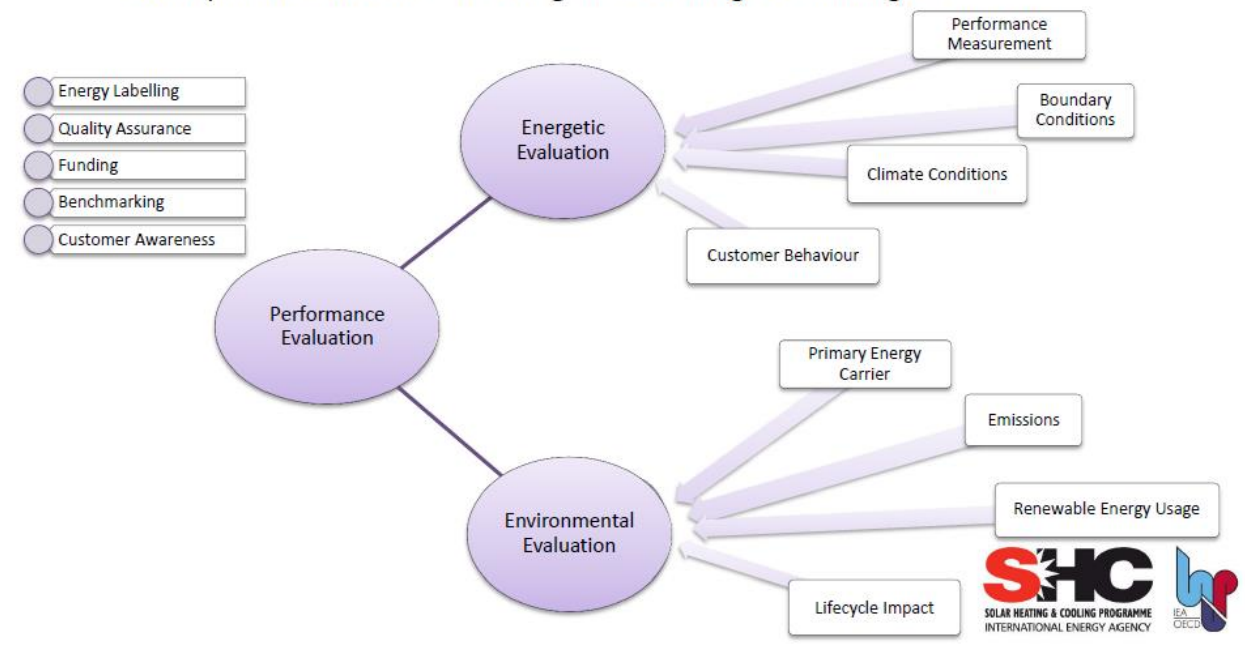


Seasonal Performance factor - SPF

The SPF gives the efficiency of the whole system or a defined subsystem, calculated as the overall useful energy output to the overall driving final energy input.

$S P F=\frac{\int\left(\dot{Q}_{S H}+\dot{Q}_{D H W}+\dot{Q}_{C}\right) \cdot d t}{\int \sum P_{e l} \cdot d t}$

- Difficult to determine if system is operated simultaneously in different operation modes, e.g. heating and cooling, cooling and DHW etc.

- The SPF accounts for the system performance depending on the boundary conditions such as heat source temperature, solar irradiation, supply temperature etc.

- It does not take into account the depletion of non-renewables or $\mathrm{CO}_{2}$ emissions caused during the lifetime etc.

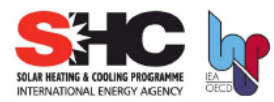

SHP Reference System - Square View

SOLAR+HEAT PUMP

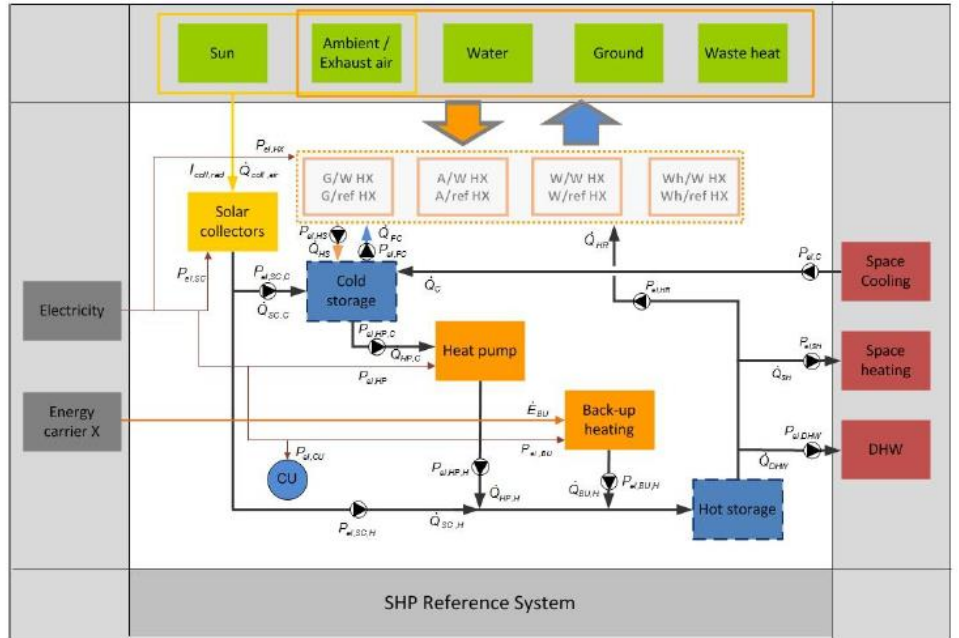




\section{SHP Reference System - Simplifications}

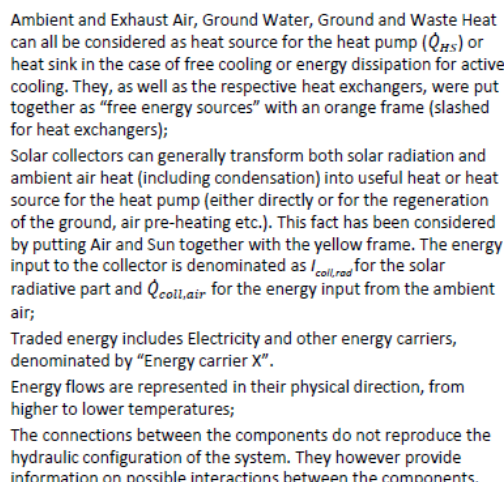

Solar collectors can Solar collectors can generally transform both solar radiation and ambient air heat (including condensation) into useful heat or heat of the erot hat by puttin Air and sen to by putting Air and Sun together with the yellow frame. The energy radiative part and $Q_{\text {coll air }}$ for the energy input from the ambient

Traded energy includes Electricity and other energy carriers, Traded energy includes Electricity and

denom Energy flows are represented in their physical direction, from higher to lower temperatures:

The connections between the components do not reproduce th hydraulic configuration of the system. They however provide due to the hydraulics and the controls of the system;
The connections between components with a pump symbol represent energy consumption needed to transport the heat system;

The components presented with a slashed frame (both storages) can be ignored if not a part of a particular system or if direct connections possible (e. the solar energy can be either stored or used directly in the evaporator of the heat pump);

Although presented as one component, the "stora" can actually consist of more than one unit (eg one storage for heting and one for DHW). This implies, that 0 . the energ input $P$ a reality consist of more than one consumer (pumps);

in analogy, one pump can be used to transport the heat tran ter In analogy, one pump can be used to transport the heat transfer sink" components. For example, one pump can be used to circulate the fluid from the collector both to the evaporator of the heat pump and to the heat storage. This implies, that this pump would be consuming both $P$ and $P$. This has to be considered for the evaluation of the data accordingly Defrosting for air source HPS:

- Direct electric defrosting: Should be included in $P_{\text {e, HPP }}$ Hot gas defrosting: The energy consumption should also be included in $P_{\text {eli }, H}$ i

Reverse cycle defrosting: the heat energy taken from the storage/building has to be subtracted from the useful energy output at the appropriate boundary, if not automatically executed by the heat meter.

\section{System Boundaries}

Four different boundaries have been defined to evaluate a SHP system:

1. „SHP+" Solar and Heat Pump System with Useful Energy Distribution System

a. Systems without additional heating of the distribution pipes

b. Systems with additional heating of the distribution pipes

2. "SHP“ Solar and Heat Pump

3. "bSt" Before Storage

4. „HP + HS (HR)“ Heat Pump with Heat Source (Heat Rejection)

5. „HP, SC, BU“ Heat Pump, Solar Collector, Back-Up Unit

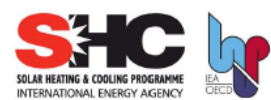


System Boundaries - SHP+

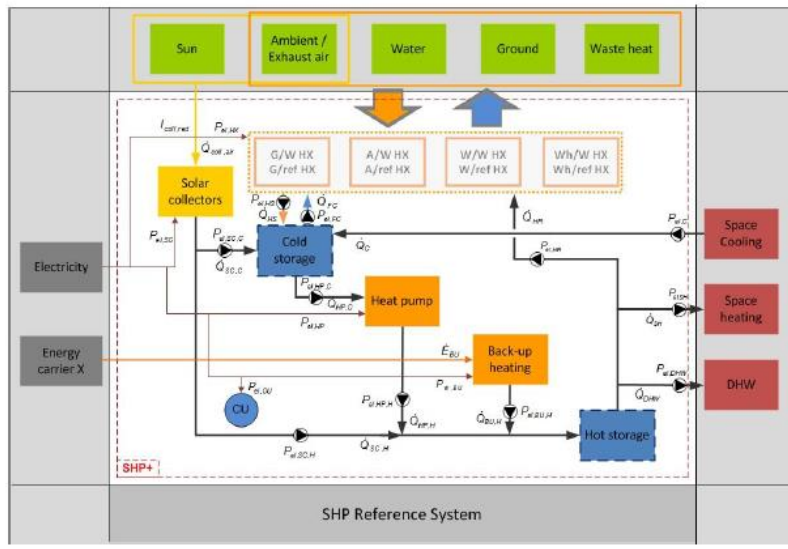

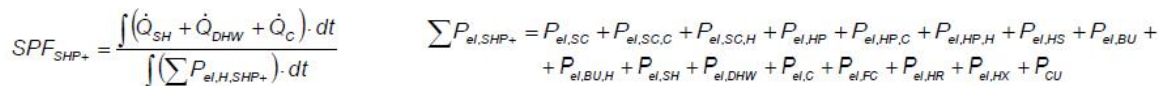

System Boundaries - SHP

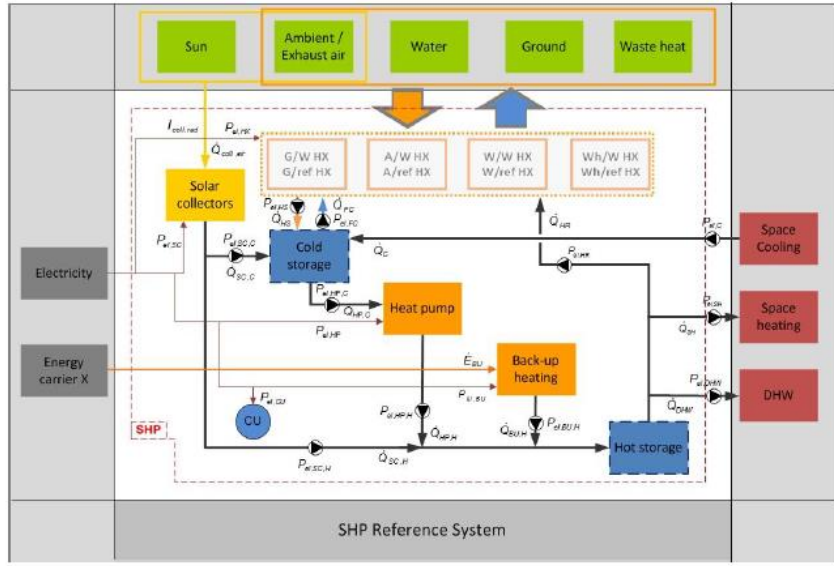

$$
S P F_{S H P}=\frac{\int\left(\dot{Q}_{S H}+\dot{Q}_{D H W}+\dot{Q}_{C}\right) \cdot d t}{\int\left(\sum P_{\text {elH.SHP }}\right) \cdot d t}
$$

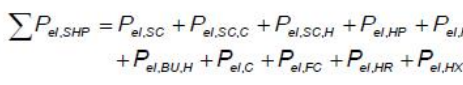


System Boundaries - bSt

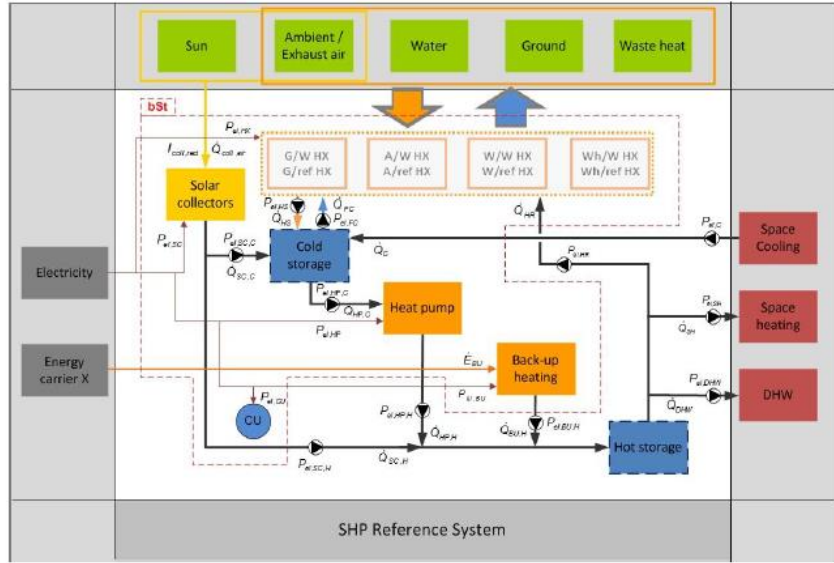

$S P F_{b S t, H e a t}=\frac{\int\left(\dot{Q}_{S C, H}+\dot{Q}_{H P, H}+\dot{Q}_{B U, H}\right) \cdot d t}{\int\left(\sum P\right.} \quad \sum P_{e l, b S t, H e a t}=P_{e l, S C}+P_{e l, S C, C}+P_{e l, H P}+P_{e l, H P, C}+P_{e l, H S}+P_{e l, F C}+P_{e l, B U}+P_{e l, H x}+P_{C U}$ $\int\left(\sum P_{\text {el,bst,Heat }}\right) \cdot d t$

System Boundaries - HP + HS

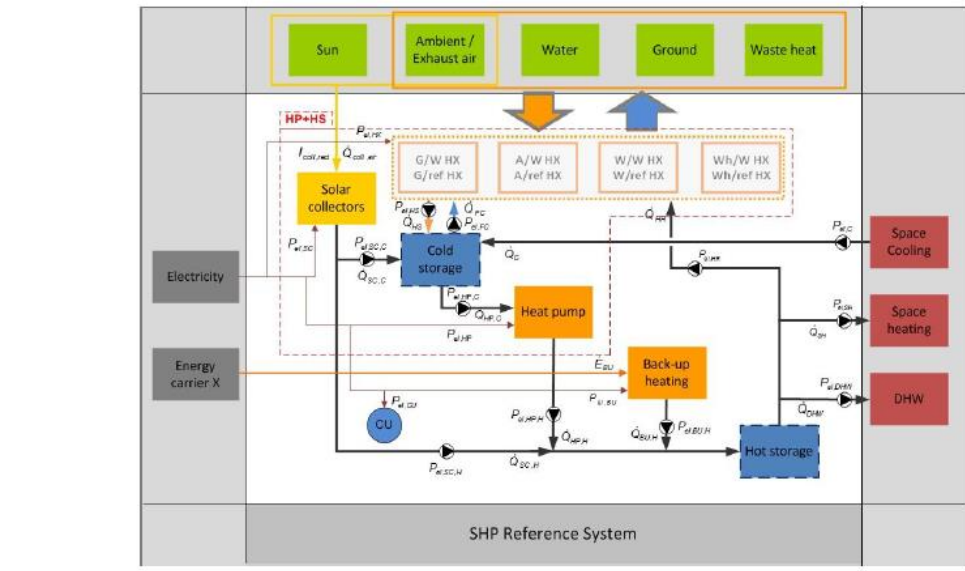

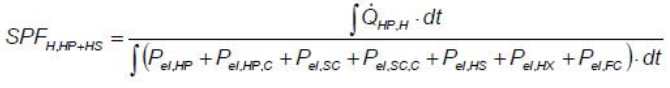




\section{System Boundaries - HP / SC / BU}

$$
S P F_{S C} \text { and } S P F_{B U} \text { analog to } S P F_{H P}
$$

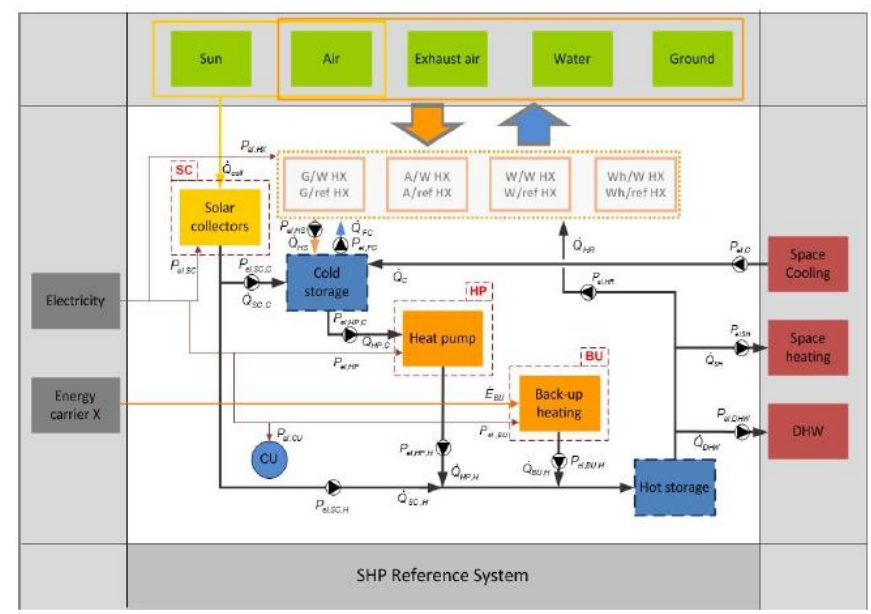

$$
\underbrace{S P F_{H P}=\frac{\int\left(\dot{Q}_{H P, H}+\dot{Q}_{H P, C}\right) \cdot d t}{\int P_{e s, H P} \cdot d t}}
$$

Overall

$$
\underbrace{S P F_{H P, H a a t}=\frac{\int \dot{Q}_{H P, H} \cdot d t}{\int P_{e, H, H} \cdot d t}}_{\text {Heating Mode }}
$$

$$
\underbrace{S P F_{H P, C o o l}=\frac{\int \dot{Q}_{H P, C} \cdot d t}{\int P_{\theta, H P, C} \cdot d t}}
$$

Cooling Mode

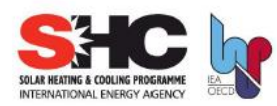

Example - Simplified Hydraulic View

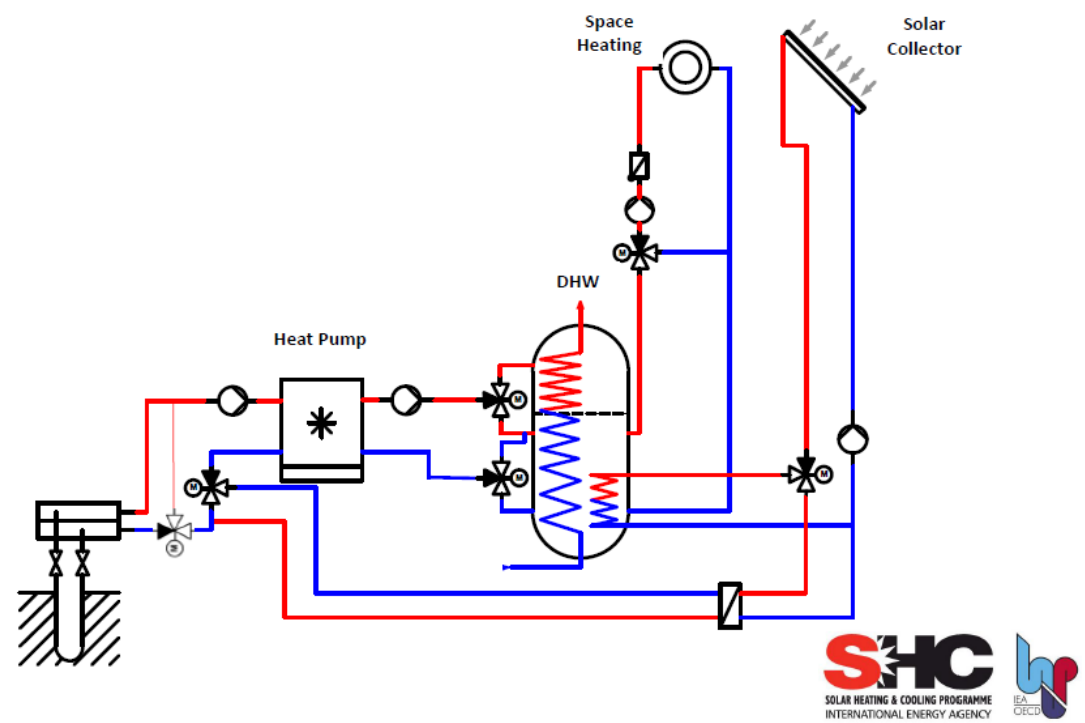




\section{Example - Square View Representation}

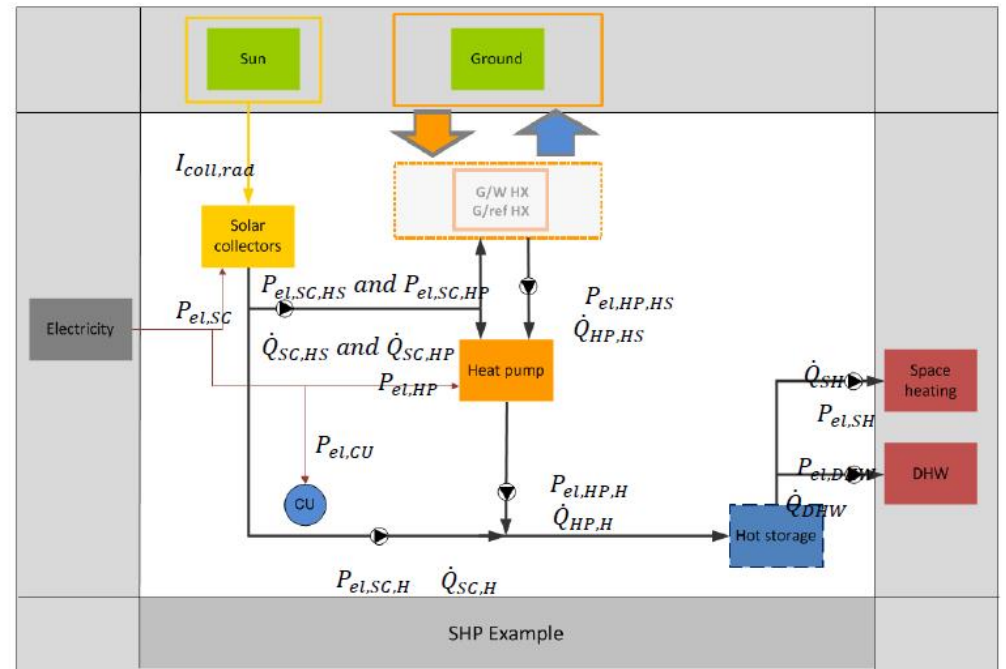

\section{Example - Square View Representation} with Quantities

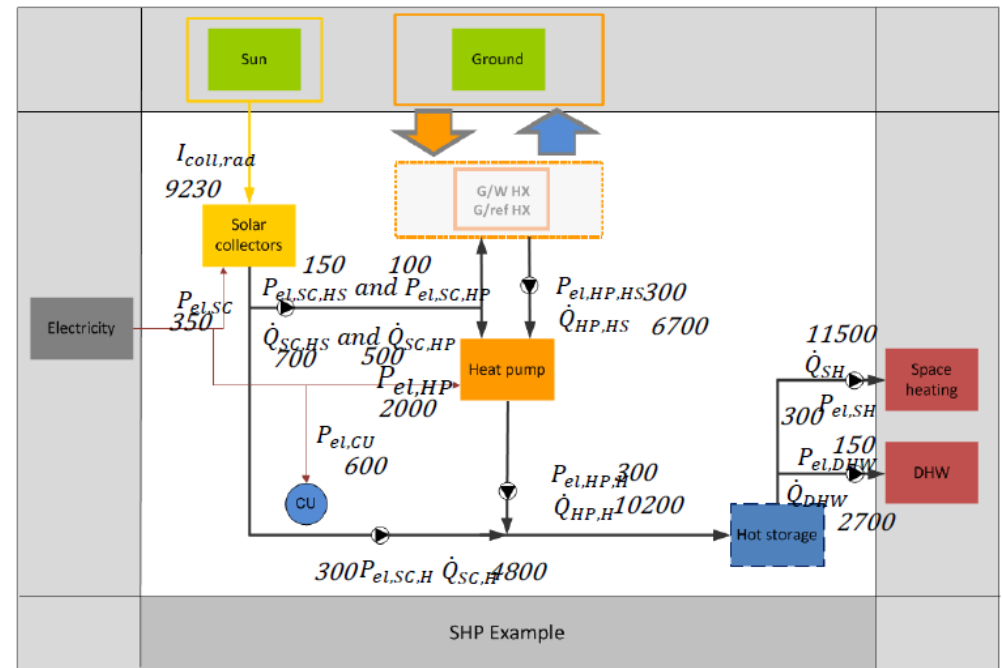


Example - SPF according to the respective boundary

- SPF-SHP+

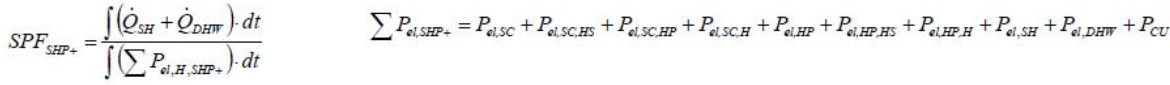

$$
\begin{aligned}
& S P F_{S S P+}=\frac{11500+2700}{4550} \quad \int\left(\sum P_{e l, H, S S P+}\right) \cdot d t=350+150+100+300+2000+300+300+300+150+600 \\
& S P F_{S P P+}=3.12
\end{aligned}
$$

Example - SPF according to the respective boundary

- SPF-SHP

$$
\begin{aligned}
& S P F_{S H P}=\frac{\int\left(\dot{S}_{S H}+\dot{Q}_{D H W}\right) \cdot d t}{\int\left(\sum P_{e l, H, S H P}\right) \cdot d t}
\end{aligned}
$$

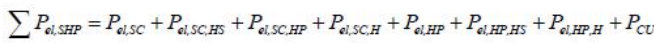

$$
\begin{aligned}
& S P F_{S H P}=\frac{11500+2700}{4100} \\
& \int\left(\sum P_{e, H, H S P P}\right) \cdot d t=350+150+100+300+2000+300+300+600 \\
& S P F_{\text {SHP }}=3.46
\end{aligned}
$$


Example - SPF according to the respective boundary

- SPF-bSt

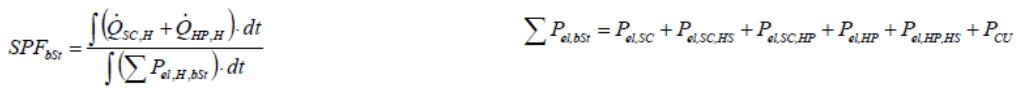

$$
\begin{aligned}
& S P F_{b S t}=\frac{4800+10200}{3500} \quad \int\left(\sum P_{e l, H, B S t}\right) \cdot d t=350+150+100+2000+300+600
\end{aligned}
$$

$S P F_{b S t}=4.29$

Example - SPF according to the respective boundary

॥ SPF $-\mathrm{HP}+\mathrm{HS}$

$$
\begin{aligned}
& S P F_{H, H P+H S}=\frac{\int \dot{Q}_{H P, H} \cdot d t}{\int\left(P_{e l, H P}+P_{e,, S C, H S}+P_{e l, S C, H P}+P_{e l, H, H S}\right) \cdot d t} \\
& S P F_{H, H P+H S}=\frac{10200}{2000+150+100+300} \\
& S P F_{H, H P+H S}=4
\end{aligned}
$$


Example - SPF according to the respective boundary

- SPF - HP and SC

$$
\begin{array}{ll}
S P F_{H P, H}=\frac{\int \dot{Q}_{H P, H} \cdot d t}{\int P_{e l, H P, H} \cdot d t} & S P F_{S C, H}=\frac{\int\left(\dot{Q}_{S C, H}+\dot{Q}_{S C, H S}+\dot{Q}_{S C, H P}\right) \cdot d t}{\int P_{e, l, S C} \cdot d t} \\
S P F_{H P, H}=\frac{10200}{2000} & S P F_{S C, H}=\frac{4800+150+100}{350} \\
S F_{H P, H}=5.1 & S P F_{S C, H}=14.42
\end{array}
$$

Example - comparison of different SPFs

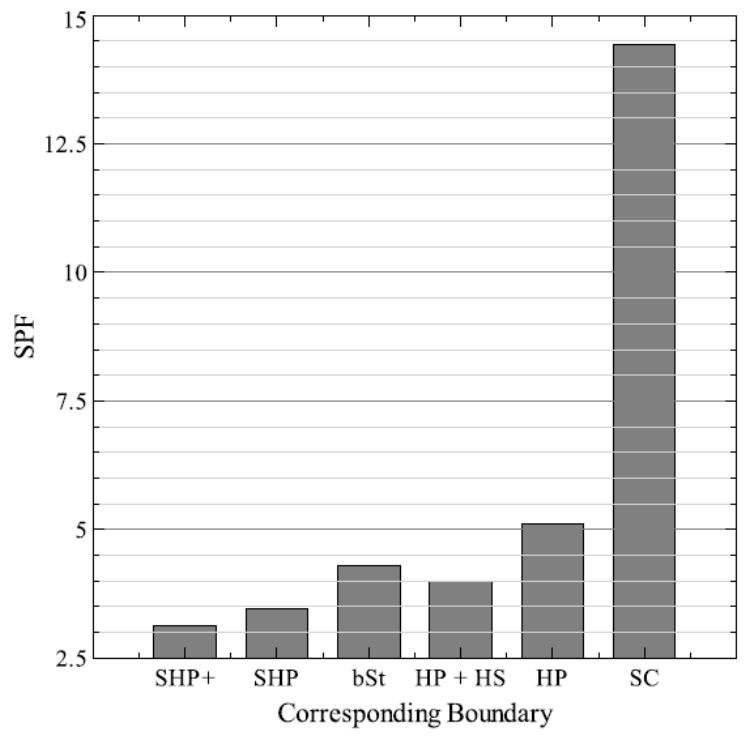




\section{Nomenclature}

CED Cumulative Energy Demand

$\dot{E} \quad$ Energy flux in W

GWP Global Warming Potential

1 Solar irradiation in W

Subscripts, capital

Back-up unit

Cooling, low temperature

Cooling operation

Control unit

Domestic hot water

Final energy

High temperature

Heat Heating operation

HP Heat pump

HR Heat rejection

$$
\text { Subscripts, small }
$$

bSt Before storage

coll Collector(s)

\section{Power in W}

Thernal power in $\mathrm{W}$

Primary Energy Ratio

Seasonal Performance Factor

Heat source

Heat exchanger

Non-renewable

Primary energy

Solar collector(s)

Space heating

Solar and heat pump

SHP+ Solar and heat pump plus energy distribution system

UE Useful energy

el Electrical

Rad Radiative 